\title{
DECISION SUPPORT FOR THE GENERAL AVIATION PILOT
}

\author{
John H. Painter \\ Wallace E. Kelly, III \\ Jeffrey A. Trang \\ Kristopher A. Lee \\ Paul A. Branham \\ of \\ Dept. of Electrical Eng. \\ Texas A\&M University \\ College Station, Texas
}

\author{
John W. Crump \\ of \\ Knowledge Based \\ Systems, Inc. \\ College Station, Texas
}

\author{
Donald T. Ward \\ Karthik Krishnamurthy \\ Dick L. Y. Woo \\ William P. Alcorn \\ Andrew C. Robbins \\ Ren-Jye Yu \\ of \\ Dept. of Aerospace Eng. \\ Texas A8.M University \\ College Station, Texas
}

\begin{abstract}
Flight management systems for large, commercial aircraft are quite common, as are inexpensive, user-friendly personal computers. Can the two ideas be combined to yield affordable, flight management systems for smaller aircraft? This paper shows the answer to be "Yes!"
\end{abstract}

Increasing air traffic control (ATC) requirements raises the workload of pilots. Required tasks dictate more "head-in-thecockpit" computation, which can easily distract a pilot from safe airplane operation. Following eight years of research, we present an on-board computational system that increases pilot situational awareness, decreases diversion to routine computations, and anticipates upcoming needs.

The key to anticipatory flight management is an expert system that uses knowledge of ATC procedures, aircraft operating procedures and limitations, and aircraft performance to infer current flight operating "mode" without direct pilot intervention or input. A flight mode interpreter (FMI) enables automatic display selection, pilot advice, and warning.

This paper reports the development of an FMIbased flight management system, called General Aviation Pilot Advisory and Training System (GAPATS), that is being developed jointly by Texas A\&M University and Knowledge Based Systems, Inc. Software development is carried out using a fixed-base engineering flight simulator. Pilot participation in all phases of development and evaluation is the norm. Flight tests have begun on an instrumented research light twin owned by the
Texas A\&M University Flight Mechanics Laboratory.

\section{INTRODUCTION}

\section{Background}

There is a compelling need for automation in the General Aviation (GA) cockpit. During the 1980 s the U.S. all but ceased production of light, piston-engined aircraft due to an increasingly adverse market environment. Whereas $18,000 \mathrm{GA}$ aircraft were produced in the U.S. in 1978, that number dwindled to 899 by 1992 . Of two leading GA manufacturers, Piper took bankruptcy [1]. Only in the late 1990 s are the factors coming into place to allow this industry to recover.

NASA's Dr. Bruce Holmes has defined a perceived-value ratio for $\mathrm{GA}$, which he believes must be improved to resuscitate the market [2]. This ratio is "What you get" divided by "What you pay." In the "get" numerator, the ease of use of the ATC system needed to be increased. In the "pay" denominator, the cost of product liability needed to be reduced. Product liability has been initially addressed in recent congressional Tort Reform legislation, and general aviation aircraft sales have been up for the past two years, encouraging the FAA to predict a growth in the active aircraft fleet of over 15,000 units between 1996 and 2008 [3]. But this rosy growth pattern is based on a number of assumptions, and the report warns, "...the actual rate of growth will depend on how successful the industry is in stimulating the development of new general aviation products and services." The ATC ease-of-use factor, a component of Holmes' "get" numerator, responds to new avionics technology. 
The difficulty of using the ATC system is, for the GA pilot, largely a matter of information processing and management. Historically, such processing was done without computer help. It was the pilot who mentally integrated aircraft sensor information required for stable aircraft flight under Instrument Flight Rule (IFR) conditions. He formulated and reformulated flight control inputs to follow ATC clearances, according to the rules of flight for his particular aircraft. With regard to pilot functions such as these, new computing technology may significantly alter the perceived value of General Aviation.

\section{New Technology}

Knowledge-based computer processing technology may aid the pilot in easily processing and managing information necessary for the ATC system. Computer software can mimic, to a certain extent, the mental procedures a pilot uses to manage the flight of his aircraft in response to clearance instructions. The key to success in computeraugmenting a pilot's mental skills is in not taking him "out-of-the-loop." There are two fundamental rules. First, the new technology must reduce the pilot's net workload. Second, the computer must increase, not reduce, the pilot's situational awareness.

The software's main functions are to sharpen and direct the pilot's situational focus while protecting him from information overload or computational saturation. Both functions may be realized by the software recognizing the current flight situation, based on stored rules and real-time sensory data, without pilot input other than current flight plan and ATC clearance.

Airplanes that are under ATC guidance generally perform flying operations which may be recognized by looking at aircraft flight variables such as altitude, airspeed, rate of climb/descent, direction of flight, and navigational position. These may be thought of as defining a "state-space" in which the aircraft operates. Operating modes, such as take-off, climb-out, cruise, hold, initialapproach, final-approach, land, and go-around cause the aircraft to occupy different regions in the state-space. If these regions can be defined so that they do not overlap appreciably, then decisions on "flight mode" can be unique and made with high confidence.
Even when the aircraft is traversing from one mode to the next, trends may be computed which, coupled with rules, can make the flight mode decision highly accurate. Software which makes such "decisions" is called a Flight Mode Interpreter (FMI).

The availability of an FMI enables other automatic functions, such as a Pilot Advisor (PA) and mode-driven displays. The PA, which is rule-based, provides the pilot the data necessary for the airplane to fulfill the ATC clearance. The combination of FMI, PA, and appropriate displays comprises a complete system.

\section{RESEARCH AND DEVELOPMENT}

\section{Prior Work}

The present work was motivated by a 1986 Air Force program, called Pilot's Associate [4]. Many of the original ideas in Pilot's Associate are realized in GAPATS. Our present work, however, is based on NASA-supported research from 1989 through 1994 [5]. In that project, the basic technology for the FMI was developed. The present follow-on work is to create a flight-tested entire engineering prototype system. Our evolved design is a joint effort between Texas A\&M University and Knowledge Based Systems, Inc., of College Station, TX, under a NASA Small-Business Technology Transfer (STTR) contract entitled General Aviation Pilot Advisor and Training System (GAPATS). A State of Texas Advanced Technology Program grant, titled Computing for the Smart Cockpit, supported necessary advances in the underlying technology, such as fuzzy logic, plus improvements to the University research infrastructure. The latter included an upgraded Electronic Flight Simulator (EFS).

The 1989-1994 NASA-supported research showed fuzzy logic to be a viable method for implementing the FMI. In fact, in the prior work, fuzzy control was actually used to maneuver the aircraft [6] and to operate its flaps [7]. In the work subsequent to 1995, the closed control loop was opened and the fuzzy controller replaced by a crisp rule-based PilotAdvisor (PA). This attended the change in focus from high-end commercial jet transports to low-end GA operations. The role of the FMI remained the same, but the role of the PA replaced that of the fuzzy controller that had 
hitherto formulated commands to drive the auto-pilot. Now, the PA formulates instructions for the pilot to implement manually or through the auto-pilot, much in the spirit of a flight director. The PA, through its explanation facility, may also critique the pilot's technique, in a training mode of operation.

\section{System Architecture}

Figure 1 shows the architecture of the system. It is a control loop, closed through the pilot. Aircraft sensors, including the Global Positioning System (GPS), provide the basic state-variable data that drive the system. These data are input to three software modules: the Flight mode Interpreter (FMI), the Pilot Advisor (PA), and a Navigation Module and Flight Director (NAV).

NAV is a supporting module that computes quantities needed by both the PA and the FMI. The FMI provides the current identified flight mode to the PA which, in turn, controls two pilot displays, the Head-Up Display (HUD) and the Head-Down Display (HDD). Both these displays are adapted to the current flight mode. The HUD provides real-time maneuvering instructions while the HDD provides navigation information. The HDD also provides the input mechanism for the pilot to communicate with the system.

\section{Development Environment}

The system development environment is distributed over two University departments and one small business. The system runs on a PC on-board the aircraft, which, for developmental purposes, is a Commander 700 , a typical GA light twin. The testbed aircraft is hangared and maintained at the University's nearby Riverside Campus, a former Air Force training base.

The software is integrated and tested in the Electronic Flight Simulator, a facility comprising a fixed-based dual cockpit (Figure 2) with HUD and HDD, a three-screen projection of imagery generated by a PC and a Silicon Graphics Onyx Reality 2 computer (Figure 3). In the simulator the PC replicates the aircraft flight computer and communicates via Internet with the Onyx, which performs trajectory calculations and generates the scenery projections. The PC receives the simulated aircraft measurements and generates the displays for the HUD and HDD in the cockpit. The simulated flight scenery and navigational aids are from the Waco and College Station approach control areas where the actual flight tests are being flown.

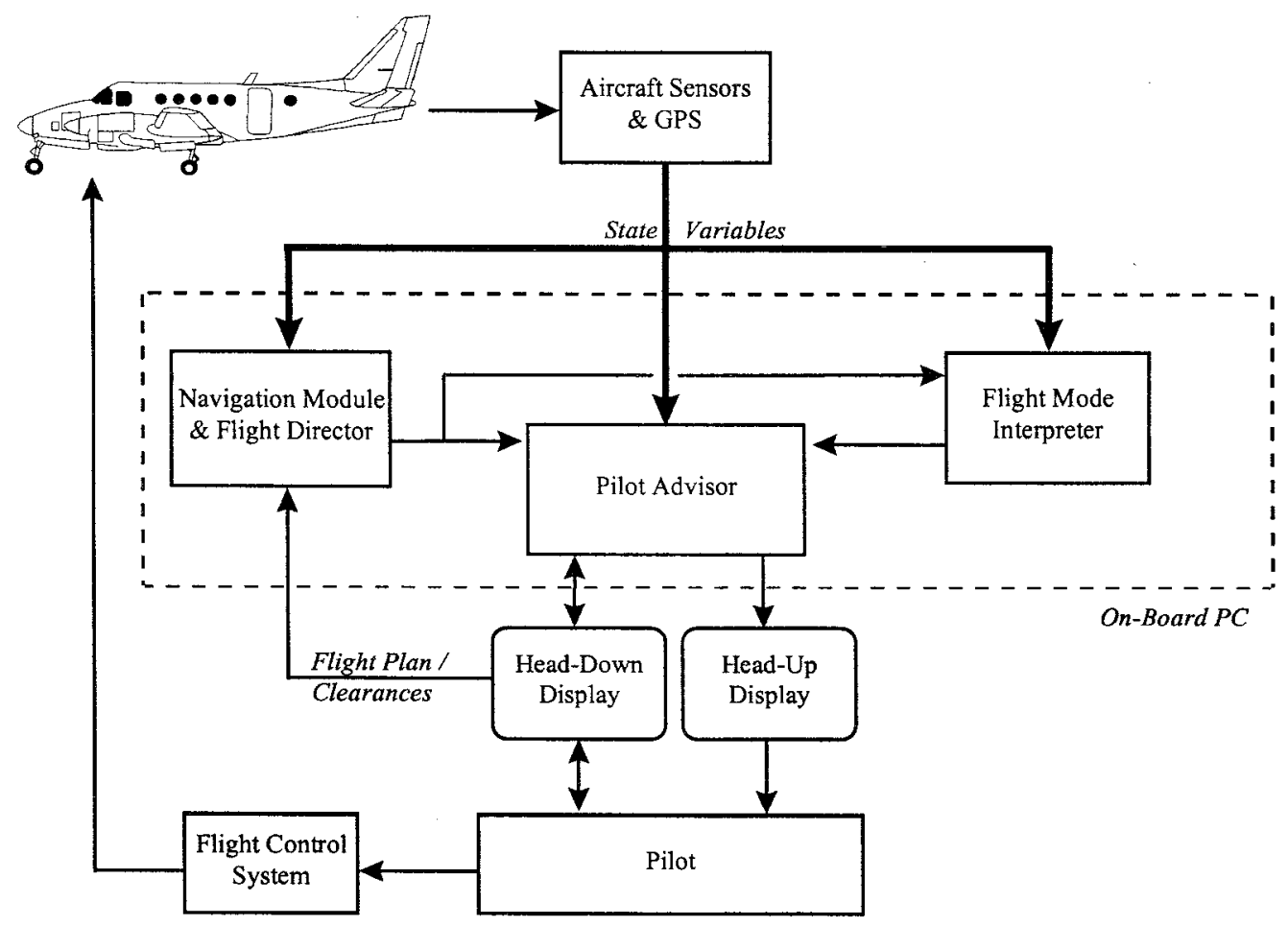

Figure 1. System Architecture 


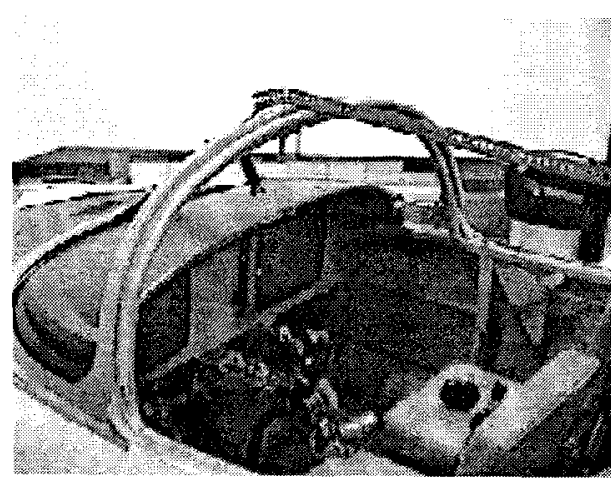

Figure 2. Flight Simulator Cockpit.

\section{FLIGHT MODE INTERPRETER}

The FMI models the flight modes as fuzzy sets defined in the multidimensional state space of the flight variables. The $\mathrm{N}$-dimensional models can be composed from one-dimensional fuzzy sets defined in the domains of each variable. However, traditional fuzzy rule-base composition assumes uncorrelated state variables, which is not the case for the flight mode interpretation problem. Kelly and Painter [8] have addressed this issue and extended the state-of-the-art of fuzzy engineering through hypertrapezoidal fuzzy membership functions (HFMF). An HFMF-based FMI is the first application of this new technique for designing $\mathrm{N}$-dimensional fuzzy membership functions.

The inputs to the FMI include aircraft state variables (e.g. altitude, airspeed, rate of climb, etc.) and distances related to the flight plan (e.g., distances to initial approach fix, final approach fix, etc.) The FMI partitions the state space of these inputs into the flight modes and uses the fuzzy degree of membership as an indication of the certainty of the FMI flight mode decision.

The FMI's performance is measured by how closely its mode decision matches the intended mode of an expert pilot. During testing of the FMI, the pilot indicates what mode best

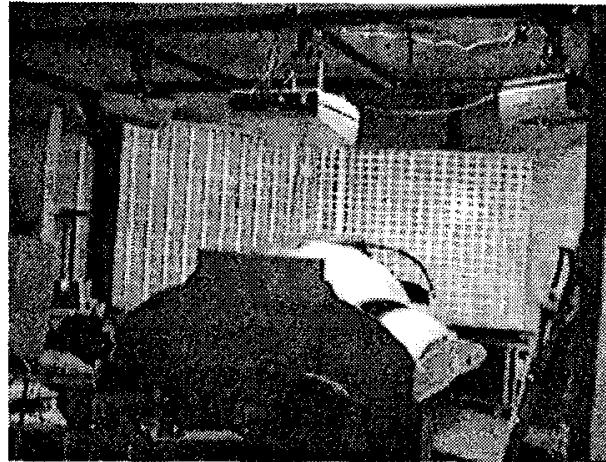

Figure 3. Simulator Projection System.

characterizes the current situation. The FMI should come reasonably close to selecting the same mode, its decision based solely on sensor data. The plot of Figure 4 is an example of the FMI's ability to infer what the pilot considers to be the modes for an entire flight from takeoff to touchdown. This plot was generated using flight data for a Rockwell Commander 700 aircraft model in the Engineering Flight Simulator.

With enhancements such as decision filtering and mode memory, the GAPATS FMI produces a timely decision of flight procedure, independent of pilot input. An FMI based on hypertrapezoidal fuzzy membership functions also shows potential for automatic training of FMI parameters for application to a wide range of aircraft.

\section{PILOT ADVISOR}

The Pilot Advisor (PA) lies at the heart of the system and serves as the central control point for the outer modules. Based on an embedded rule-based engine, the $\mathrm{PA}$ establishes a powerful expert system foundation for the system to provide advice to the pilot. After the FMI determines the correct flight mode and reports it to the PA, the PA draws on the sensor data and the detailed rule-base to provide proper and timely advice to the pilot.

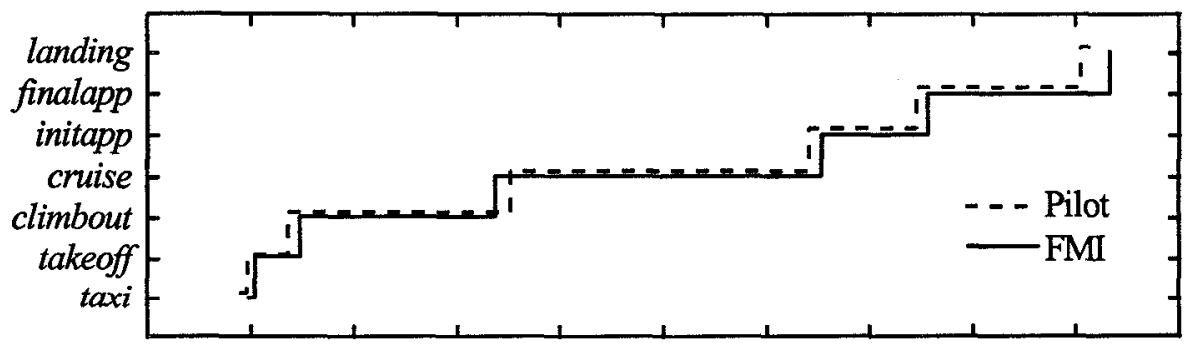

Flight time

Figure 4. Pilot Indicated and Computer Inferred Flight Modes. 
Each flight mode given by the FMI has its own set of rules in the PA's rule-base governing the state of the aircraft, warnings, advisories, and alarms. By separating the rules into modules based on the flight mode, we were able to simplify the rules, improving creation, maintenance, and comprehensibility of the rule-base. Yet another benefit is that the rules run faster due to the modularity provided by the different flight modes.

As the flight progresses, the FMI continuously feeds the mode information to the PA that iterates through the rule-base, using the mode and sensor data as well as input supplied by the pilot and the navigation module. The PA examines the incoming data and fires the matching rules from the rule-base. The rules specify which messages to send to the pilot via the HUD and the HDD.

The PA has another function in that it must communicate which configuration should be used on both the HUD and HDD. This provides the pilot with the best HUD/HDD layout for the current state of the aircraft. This provides the pilot with improved situational awareness and reduces the number of tasks by providing essential information at the proper time. The combination of both fuzzy (FMI) and rulebased (PA) techniques has significantly simplified the development of this system. The FMI efficiently determines the flight mode using fuzzy logic, which would be very complex to program into any production rule system. Similarly, the rule-base easily chooses the HUD/HDD configuration and produces advisories after being given the selected mode, with much less effort than it would take using a similar fuzzy-based solution. Combining the two techniques to generate these complementary effects has produced a viable, effective pilot advisory system that may not otherwise have existed.

\section{SYSTEM DEVELOPMENT AND EVALUATION}

The development of GAPATS software has been based on early and strong pilot input to the design. The key philosophy brought from the Pilot's Associate program to GAPATS is that the pilot must always be in charge of the system. If GAPATS does not improve the situational awareness of the GA pilot, it has failed. To realize this end goal, the development team largely predicated development decisions on simulation evaluations of early software module implementations and of the evolving integrated system. Continuous pilot flying evaluation of the software became an overriding software design consideration.

An early example of this "code-simulate-fly approach" was the development of display formats. A decision was made early in the program to utilize a HUD because information can be summarized more readily on such a device and because it allows the GA pilot to fly instrument procedures as much like visual flight as possible. Consequently, one of the first questions was "How should the HUD display look to provide information that is easy to use?" Woo [9] did the earliest formal pilot evaluation in the EFS, looking at three advanced HUD display configurations. The procedure he used is indicative of how developmental testing is proceeding. A total of 6 pilots of varying experience levels flew a specific instrument landing task; they then gave their opinion evaluations of their spare workload capacity using the Bedford scale to correlate this subjective opinion. In addition to this subjective measure of display effectiveness, a quantitative index of how closely each pilot followed the published procedure was also calculated from simulation-generated aircraft states. Thus, both quantitative and qualitative measures of the improvements offered by the new HUD displays were used to choose further refinements. This iterative design approach, guided by input from users, is the hallmark of GAPATS developmental evaluation.

More recently, the integrated software system has been "flown" by the first set of evaluation pilots in the upgraded EFS. This upgrade to the fixed-base simulator, largely funded by the Texas Advanced Technology Program grant for Computing for the Smart Cockpit, became operational in July and, after all software modules were installed and verified, evaluation simulations were flown during the late summer. Data analysis is not yet complete, but it is anticipated that flight tests with modified software will be flown in October or November.

The testbed aircraft for these flight evaluations is shown in Figure 5. This Commander 700 has been outfitted with a suite of sensors that GAPATS' FMI needs to infer the nominal flight 
mode. This sensor suite is summarized in Table I.

Table I. GAPATS Flight Test Sensor Suite

\begin{tabular}{|c|c|c|}
\hline Sensor & Type & Status \\
\hline Pitot-Static & $\begin{array}{c}\text { Pressure } \\
\text { Transducer }\end{array}$ & Installed \\
\hline Flow Direction & $\begin{array}{l}\text { Vanes with } \\
\text { encoders }\end{array}$ & Installed \\
\hline Attitude & Euler Angles & Installed \\
\hline $\begin{array}{l}\text { Engine Data } \\
\text { (RPM, fuel } \\
\text { pressure, oil } \\
\text { temp, oil } \\
\text { pressure, CHT, } \\
\text { EGT, fuel flow, } \\
\text { manifold } \\
\text { pressure) }\end{array}$ & $\begin{array}{c}\text { Rocky } \\
\text { Mountain } \\
\text { Instruments }\end{array}$ & Installed \\
\hline $\begin{array}{l}\text { Navigation } \\
\text { (GPS with } \\
\text { moving map, } \\
\text { heading) }\end{array}$ & $\begin{array}{l}\text { MentorPlus } \\
\text { G100 }\end{array}$ & Portable \\
\hline $\begin{array}{c}\text { Flat Panel } \\
\text { (HDD) }\end{array}$ & $\begin{array}{c}\text { Marshall } \\
\text { Industries }\end{array}$ & Installed \\
\hline HUD & $\begin{array}{c}\text { (AV8B } \\
\text { system) }\end{array}$ & Installed \\
\hline Gear/Flap & $\begin{array}{c}\text { Microswitche } \\
\text { s } \\
\end{array}$ & Installed \\
\hline $\begin{array}{c}\text { Data } \\
\text { Acquisition }\end{array}$ & $\begin{array}{l}\text { Pentium with } \\
\text { PCMCIA } \\
\text { cards }\end{array}$ & Installed \\
\hline
\end{tabular}

This sensor suite (and the included displays) is for development use only. Further refinement is necessary for flight certification. The flight test evaluation to be flown this Fall is the final step in system evolution before it goes into the FAA certification, the last step in transforming this prototype software into a commercial product.

\section{CONCLUSION}

Above and beyond the obvious technical results, this paper shows an example of nontrivial avionics development being successfully pursued in a joint academic/industrial environment. The value to the students of participation in this project was very high. The successful completion of this highly productive work was due to the quality of the involved students and to the academic application of leadership techniques flowing from the USAF, NASA, and commercial backgrounds of the principals. This project is held out as a model for similar joint efforts between academic and industrial organizations.

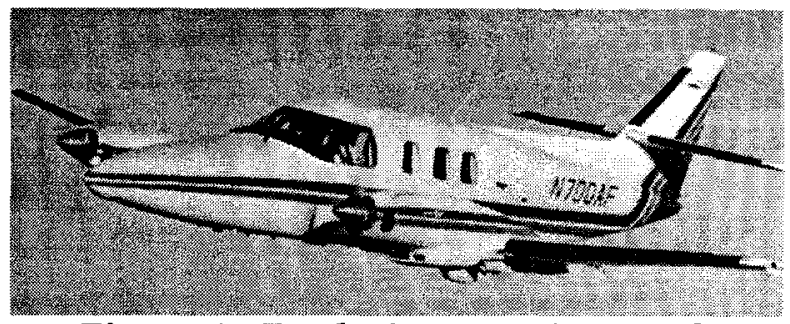

Figure 5. Testbed Research Aircraft

\section{BIBLIOGRAPHY}

[1] Anon. "General Aviation Task Force Report," Headquarters National Aeronautics and Space Administration, Washington, DC, Sept. 1993, p. 1.

[2] Bruce Holmes, "The Ingredients of a Renaissance: A Vision and Technology Strategy for U.S. General Aviation," Proceedings of the 4th Annual FAA General Aviation Forecast Conference, San Antonio, TX, March 17-18, 1994.

[3] "FAA Issues Rosy 10-Year Forecast," Flying, Vol. 124, No. 6, June 1997, p. 27.

[4] Lockheed Aeronautical Systems Company, "Final Report of the Pilot's Associate Program," Technical Report WL-TR-93-3090, Wright Patterson Air Force Base, Ohio, July 1993 (export restrictions - limited distribution).

[5] John H. Painter, Emily Glass, Gregory Economides, and Paul Russell, "Knowledge-based Processing for Aircraft Flight Control," NASA Contractor Report 194976, Langley Research Center, Hampton, VA, October, 1994.

[6] Steven Lee Lass, "An Object-Oriented, Knowledge-Based Aircraft Approach Controller," M.S. Thesis, Texas A\&M University, May 1995, available from University Microfilms, Ann Arbor, MI.

[7] Emily A. Glass and John H. Painter, "ObjectOriented Design of Discrete Fuzzy Control for Aircraft Flaps," Proceedings $2^{\text {nd }}$ Intl. Workshop on Industrial Fuzzy Control and Intelligent Systems, College Station, TX, Dec. 2-4, 1992, pp. 108-112.

[8] Wallace E. Kelly, III and John H. Painter, "Hypertrapezoidal Fuzzy Membership Functions," Proceedings of the 5th IEEE International Conference on Fuzzy Systems, New Orleans, LA, September 8 , 1996, pp. 1279-1284.

[9] Donald T. Ward and Dick L. Y. Woo, "A Simulator Study of Advanced Head-Up Display Symbology for Use in General Aviation Aircraft," AIAA Paper 97-0224, 35th Aerospace Sciences Meeting and Exhibit, Reno, NV, Jan 6-10, 1997. 